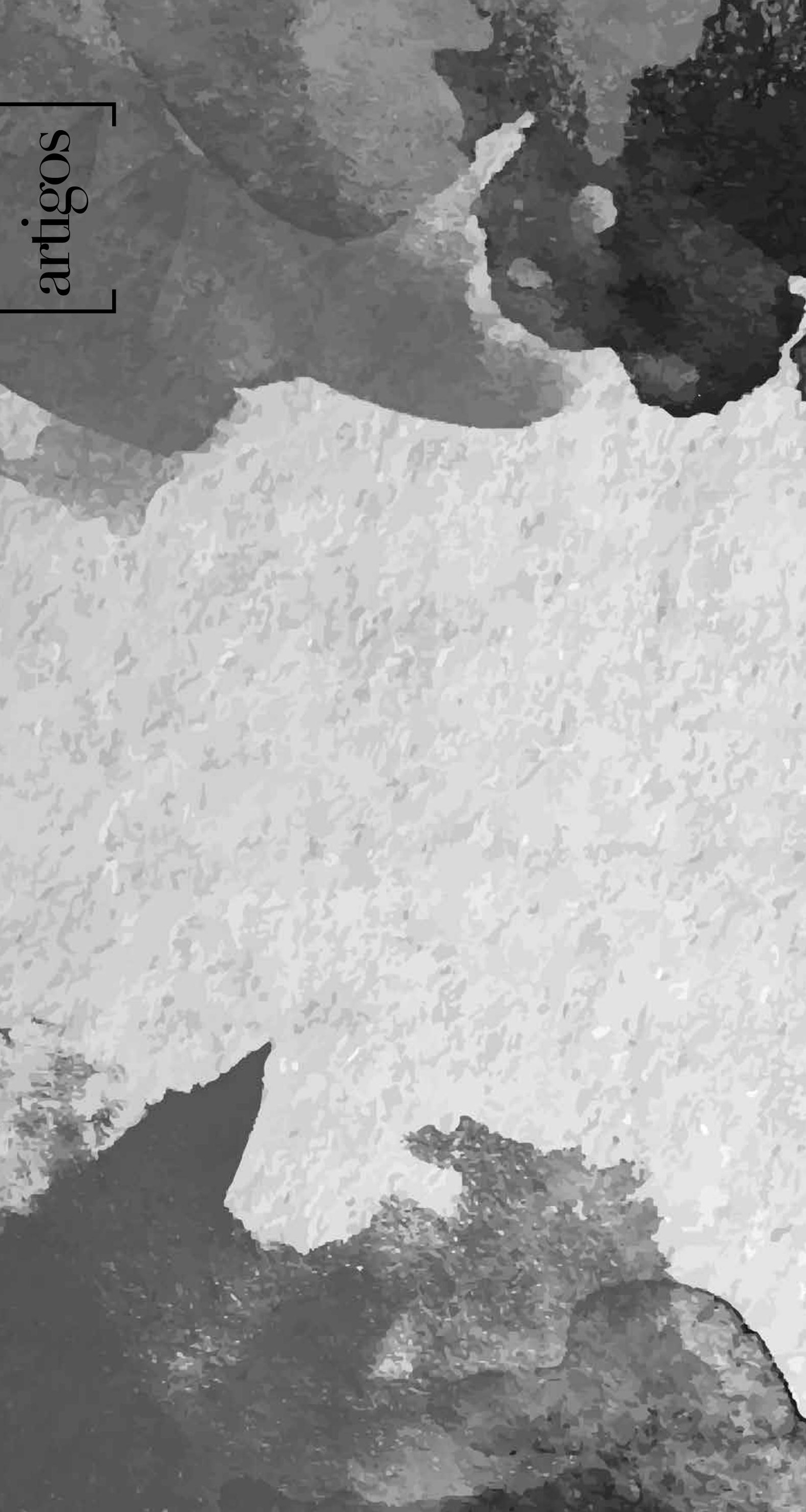




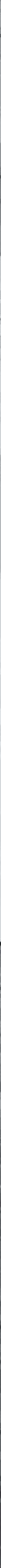




\title{
Tradução e transcriação em figurino
}

\author{
Translation and transcreation \\ in costume design
}

[n8] [resumo] "0 que criamos em moda?", "0 que a moda traduz?": estas são algumas questões apresentadas neste artigo. A pesquisa leva à construção do figurino como campo de estudo da moda, em sua relação direta com a produção de narratividade e subjetividade. 0 artigo traz o movimento de transcriação que materializa uma forma textual em imagens vestiveis.

\section{palavras-chave}

criação; tradução; transcriação; moda;

figurino.

[abstract] "What do we create in fashion?", "What does fashion translate?": these are some questions presented in this paper. The research is directed to the process in which the costume design is made, characterized as the field of study in Fashion, and the direct relationship between this process and the production of narrativity and subjectivity. This paper presents the movement of transcreation that materializes a textual form in wearable images.

[keywords] creation; translation; transcreation; fashion; costumes. 


\section{O que a moda transcria?}

Para pensar a moda em suas possibilidades tradutórias, este artigo explora a noção de "tradução criativa" ou "transcriação", teoria do tradutor e poeta Haroldo de Campos (2011). Diante da impossibilidade tradutória plena entre línguas, Campos apresenta a função de re-criação de textos, colocando a tradução como atividade criativa. A outra língua do texto traduzido traz uma nova informação estética autônoma. Original e tradução estão ligados por uma relação de isomorfia, sendo diferentes enquanto linguagens, mas cristalizando-se em um mesmo sistema (CAMPOS, 2006). Transcriar, para o autor, refere-se a uma apropriação transformadora de forças do texto de partida. Essa desconstrução e reconstrução do texto se dá na tradução de formas, o que leva o pensamento além da tradução de palavras, mas à "tradução intersemiótica" (PLAZA, 2003), de uma forma sígnica a outra.

0 que "criam" as criações da moda? No design de moda, falamos o tempo todo em criação: criação de moda, necessidades criativas, criar coleções... Este estudo inicia sua investigação sobre o que de fato a moda cria como disciplina e como campo de conhecimento. 0 que criamos, no sentido deleuziano (DELEUZE, 2003), quando fazemos moda?

Deleuze atribui uma atividade criadora a cada disciplina: a filosofia cria conceitos; o cineasta; imagens em movimento, isto é, ele fabrica blocos de movimento/duração (DELEUZE, 2003); e a ciência cria funções (DELEUZE, 1997). Ao tratar o pensamento como criação, Deleuze se questionará, 0 que é o ato de criação?

0 que acontece quando dizemos: "Ei, tive uma ideia?" Porque, de
um lado, todo mundo sabe muito bem que ter uma ideia é algo
que acontece raramente, é uma espécie de festa, pouco corrente. E
depois, de outro lado, ter uma ideia não é algo genérico. Não temos
uma ideia em geral. Uma ideia, assim como aquele que tem a ideia,
já está destinada a este ou àquele domínio. (DELEUZE, 2003, p. 291)

Rosane Preciosa (2006), ao trazer algumas reflexões sobre a atividade criadora do designer de moda na sua cultura, invoca Maria Ruckie (apud PRECIOSA, 2006): "É importante gerar o insólito para gerarmos uma nova ordem". Dessa forma, que espécies de projetos em design de moda são possiveis para subverter ordens e "inventar outros territórios de criação" (PRECIOSA, 2006, p.147)? Computando nossas reflexões sobre inovação e sobre a raridade da capacidade de nos surpreendemos na contemporaneidade, a questão sobre o "ato criativo" em moda se torna ainda mais complexa.

Podemos pensar o criador de moda "como um cronista de nosso tempo, pois ele dá visibilidade à nossa subjetividade na medida em que nos apresenta que 'segundas peles' cobrirão as nossas peles orgânicas" (PRECIOSA, 2006, p. 147). A autora apresenta a leitura-tradução desse território contemporâneo como uma das funções do designer de moda e, além disso, questiona: " não poderiamos arriscar a dizer que o designer de moda aspira a realizar, e chega mesmo de alguma maneira a realizar, uma poética das roupas?" (idem).

Ao pensar a criação de moda por sua função poética, esta pesquisa é levada à investigação de uma tradução poética das roupas. A partir da atividade criadora da moda, surge, então, outra reflexão: o que as roupas traduzem?

Assumindo o mesmo posicionamento do filólogo russo Roman Jakobson (2007, p. 72) de que "a poesia, por definição, é intraduzivel", pura e simplesmente 
de uma língua para outra, assumimos a tradução de formas da moda, como um movimento de "transposição criativa".

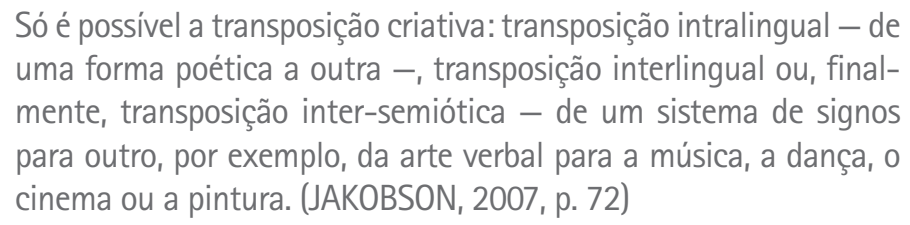

Para estudarmos o processo criador da moda por via da tradução de formas, devemos lidar com essa transcriação de subjetividades que dá forma às matérias, em uma poética do traduzir. A moda, como lugar semiótico, espaço operatório de transposição criativa ou transpoetização (CORAZZA, 2015), não busca o sentido verdadeiro de uma língua para transferi-lo a outra, mas, uma tradução de formas: levada pela potência da subjetividade em se materializar como vestes corporais.

A tradução transcriadora permite pensarmos o que cada área ou disciplina traduz em suas funções e como podemos pensar a tradução re-criadora de conceitos de uma área a outra (ACOM, 2015). 0 ato de transferir trazendo um conteúdo original de um campo para outro.

\section{Transcriação poética do figurino}

Ao lidar com a tradução poética na moda, na busca pelo o que as roupas traduzem, a pesquisa se depara com a criação de figurinos. Pela própria caracteristica da moda como campo transdisciplinar em construção, poderíamos pensar seus processos criadores-tradutórios por diferentes perspectivas, como a criação comercial e a conceitual, a temática editorial e os projetos de coleções, entre outros. No entanto, a escolha deste artigo como campo de pesquisa por dentro da moda será o processo de composição tradutório do figurino, com alguns destaques para o figurino teatral e, sobretudo, especificamente o teatro que lida com a transposição de um texto para o palco. Mesmo que essa não seja a única forma de transpor-traduzir um espetáculo.

[...] proponho chamar de teatro o produto da relação de colaboração entre o texto e o palco, no sentido amplo com o qual definimos palco. De acordo com esta definição não existiu e não existe um só teatro, mas muitos teatros existiram e existem, tantos quantos são os tipos particulares de relacionamentos efetivos contraídos entre o texto e o palco. (RUFFINI, 1995, p. 238)

A intenção deste artigo não é dar conta do processo de criação do figurino ou do próprio ator em função de um texto ou na ausência deste, e sim pensar algumas possibilidades tradutórias estéticas de um figurino. Nesse caso, a escolha versa sobre a passagem do texto para a roupa, pois é um processo tradutório recorrente, fortemente vinculado ao processo criativo também do cinema, onde temos um roteiro a ser materializado em imagens em movimento, e por sua vez, personagens a serem vestidos como parte dessa passagem material identitária do texto ao filme (CARRIĖRE, 1995). A pesquisa não ignora a dança como tradução-narrativa através do corpo, por exemplo; ou o figurino que pode pautar espetáculos de naturezas distintas, ou ainda, as formas expressivas que podem se constituir através desse corpo vestido. Como o caso de concepções que não surjam a partir de um texto ou roteiro escrito, mas sim de uma outra forma, ideia ou abstração total de um espetáculo. Por uma escolha semiótica, o estudo elege a transposição do texto que lida com a existência de um personagem a ser materializado em vestes, uma das funções do figurino, mas não necessariamente a única. 
Se pensarmos em outras concepções de trajes de cena, podemos encontrar outras materialidades compostas pelo figurino, que não necessariamente trabalhem com identidades e sim com estéticas que traduzem o espetáculo em um todo cênico.

\section{Tradução intersemiótica}

Ao pensarmos a passagem intersemiótica de uma forma escrita para um signo vestivel, temos a função do figurinista: transformar matéria, transmutar papel, conteúdo de um roteiro ou peça de teatro em imagens, criar materialidades em vestes. Segundo a figurinista Rô Cortinhas (2010, p. 19), "o figurino materializa o personagem". Nesse contexto, seu criador investe em uma transcriação da indumentária cênica, que parte de um texto escrito, no qual estão concentradas todas as caracteristicas e indícios da identidade do personagem, para, então, serem traduzidos em roupas, máscaras e acessórios com funções dramáticas. 0 figurino, enquanto objeto sensivel, é capaz de produzir subjetividades, provocando no "ator acesso a um novo nivel de existência" (CORTINHAS, 2010, p. 5). É "utilizando linhas, formas, cores, proporções e volumes que essa linguagem articulada" (PUC$\mathrm{CINI}, 2009$, p. 2) do figurino se materializa.

Os caminhos polissêmicos da linguagem provocam mutações, variações e deslocamentos de sentido, nos mais diversos graus. Por vezes, alguns termos assumem novos lugares nos campos da língua, encontrando diferentes habitats nos discursos e modos de funcionamento subjetivos. (MESQUITA, 2008, p. 78)

De acordo com o teórico e professor de estudos em teatro Patrice Pavis (2008), o texto funciona como um sistema cênico em contiguidade com os atores, com o espaço e o ritmo temporal. Esta pesquisa lida com o teatro em função de um texto a ser traduzido, encenado ou adaptado. No entanto, apesar de não ser nesse momento o objeto de estudo, não se ignora as experiências pós-modernas contemporâneas e mesmo anteriores já feitas, nas quais existem distintas relações com o texto, como material não semântico, ou mesmo em narrativas e performances que lidam absolutamente com o não verbal.

Feita a ressalva, trazemos a encenação teatral em uma definição de Pavis (2008, p. 21): "ato de colocar à vista sincronicamente todos os sistemas significantes cuja interação é produtora de sentido para o espectador".

0 figurino, enquanto elemento dessa materialização produtora de sentidos e individualidades através de um personagem, refere-se a um discurso articulado por essa indumentária cênica. As vestes atuam como linguagem não verbal, que traduzem caracteres de um personagem. Trazendo a teoria de Kathia Castilho (2004) sobre um "discurso articulado da moda" para o estudo do figurino, podemos pensar essa indumentária cênica como linguagem não verbal, que traduz artisticamente em vestes um personagem. "Assim, estabelecemos a hipótese de que o corpo e traje se imbricam de modo a significar conjuntamente um discurso" (CASTILHO, 2004, p. 40). 0 corpo "figurinado" do ator compõe os movimentos e ações cênicas.

Nessa intersemiose entre corpo e traje/moda, presentifica-se um sujeito, que, já mesmo na aparência que manifesta, apresenta um discurso articulado, pois, independentemente de o corpo e a moda estarem integrados num mesmo sistema, esse sujeito identificado por um certo discurso é também capacitado por esse mesmo 
discurso, que, por sua vez, o competencializa a interagir e a ser interagido de determinada forma em seu contexto... (CASTILHO, 2004, p. 40)

"A encenação é sempre uma parábola sobre a permuta impossivel entre 0 verbal e o não-verbal" (PAVIS, 2008, p. 28), o não verbal faz falar o verbal, completando a representação e suas escolhas de montagem do texto dramático. Para Artaud (2006), que invoca o teatro de Bali, para externar algumas de suas concepções de teatro, apresenta o figurino desse lugar como um traje "ritualístico". Ele concebe a roupa cênica como "nova linguagem física baseada nos signos e não mais nas palavras" (ARTAUD, 2006, p. 56). Essa linguagem, sugerida por Artaud, é a própria expressão tradutória das vestes que ele compara a hieróglifos animados, o que dimensiona sua noção de linguagem em signos.

[...] uma espécie de roupa simbólica, de segunda roupa, que inspira uma ideia intelectual e que se relaciona, através de todos os cruzamentos de suas linhas, com todos os cruzamentos das perspectivas do ar. Estes signos espirituais têm um sentido preciso, que nos atinge apenas intuitivamente mas com violência suficiente para tornar inútil toda tradução numa linguagem lógica e discursiva. (ARTAUD, 2006, p. 56)

Artaud (2006) se refere ao leitor sígnico da roupa, e que seria inútil uma leitura lógica desses signos. Dessa forma, podemos entender essa leitura não como contrária a uma tradução em linguagem lógica e discursiva, mas sim como uma tradução estética em subjetividades, que é lida por percepções poéticas da cena.

\begin{abstract}
Esse espetáculo nos oferece uma maravilhosa composição de imagens cênicas puras, para cuja compreensão toda uma nova linguagem parece ter sido inventada: os atores com suas roupas compõem verdadeiros hieróglifos que vivem e se movem. E esses hieróglifos de três dimensões são, por sua vez, sobrebordados por um certo número de gestos, signos misteriosos que correspondem a uma certa realidade fabulosa e obscura [...] os pés dos dançarinos, no gesto de afastar as roupas, dissolvem e reviram pensamentos, sensações em estado puro. (ARTAUD, 2006, p. 64)
\end{abstract}

Pavis (2008) também traz a figuração cênica como algo da subjetividade onírica, contrária a qualquer princípio lógico de encenação e leitura, comparando-a à figuração do sonho, espécie de imagem "desfilante" em face de um texto. 0 texto é deslocado, a encenação e sua composição visual fazem surgir o que é do texto verbal ou escrito, mas que não se poderia dizer em palavras: é quase o indizível, ou qualquer coisa semelhante.

A encenação não é somente uma produção e sentido (assim, redutível aos significados), porém é também uma produção de sensações (consequentemente, de significantes que transmitem e interpelam o espectador sem que o mesmo saiba ao certo o que aquilo quer dizer). Esta percepção da materialidade do espetáculo, da corporalidade dos atores, faz parte da experiência teatral; é esta sedução, esta insatisfação do desejo que impede que a encenação se reduza a um sentido terminal e a uma decodificação de signos ou de intenções. (PAVIS, 2008, p. 29) 
0 figurino é da ordem dessa concretização textual e cênica, pertence aos elementos visuais que fazem da imagem a narrativa não verbal. São peças pertencentes ao composto de montagem do espetáculo como um todo. Dramatizar personagens em vestes, na criação do figurino, consiste em mobilizar e apropriar-se do texto para torná-lo visivel, próprio para uma concretização cênica (PAVIS, 2008). 0 figurinista se interpõe entre tradutor e encenador, preparando o terreno para a encenação ao sistematizar escolhas de dramaturgias em visualidades que efetivam o texto na cena.

[...] um tipo de enunciação gestual e rítmica a um texto; na seqüência procura-se um verbo-corpo equivalente e apropriado para a língua-alvo. É necessário, portanto, para efetuar a tradução do texto dramático, fazer-se uma imagem visual e gestual desse verbo-corpo da língua e cultura-fonte para tentar apropriar-se a partir do verbo-corpo da língua e cultura-alvo... (PAVIS, 2008, p. 140)

A construção do figurino pertence ao movimento de dramatização que coloca um texto em cena; teatralizar nas artes cênicas ou cinematizar no cinema (CUNHA, 2007): ações que refletem as relações de transcriação entre palavra e imagem. Compor um figurino faz parte do ato de adaptar um texto à cena, e esta transferência em composição poética, dramatúrgica, em certa medida, corresponde ao processo que escolhe diferentes materiais e mecanismos para transitarem entre campos conceituais e simbólicos. Na operacionalização tradutória, que se inicia na decupagem, a fim de extrair todos os elementos que caracterizam um personagem para concretizá-lo em indumentárias cênicas, o texto original se esvai e 0 encontro por materialidades sígnicas criam ressonâncias outras. A transcriação das roupas libera formas semióticas ocultas (SANTAELLA, 2005) do próprio texto, as quais dão vida à imagem e revelam uma superficie comunicativa. Essa distância semiótica entre campos, transformados em cena, compõe uma fusão de forma e conteúdo.

A tradução criativa de uma forma estética para outra, no âmbito da poesia, dispensa apresentação, tanto pela tradição qualitativa e quantitativa de trabalhos produzidos na história, quanto pela reflexão teórica relativa a este tipo de operação artística. Teorias produzidas sobretudo por artistas pensadores abriram caminho para investigações sobre tradução que vão além de características meramente linguisticas. (PLAZA, 2003, p. 12)

"No teatro a tradução passa pelo corpo dos atores e pelos ouvidos dos espectadores; não se traduz simplesmente um texto linguistico para outro: confronta-se, e faz-se comunicar graças ao palco" (PAVIS, 2008, p. 124). Essas situações gestuais e de alternâncias entre culturas heterogêneas, separadas pelo espaço e pelo tempo, se compõem mutuamente na formação tradutória da escrita textual para imagens de corpos em movimento.

Haroldo de Campos (1989) considera a "tradução intersemiótica", a interpretação dos signos verbais por meio de sistemas de signos não verbais, ou de um sistema de signos para outro, como uma das mais fascinantes formas de teorizar e praticar a tradução. Essa operação é também trabalhada pelo artista plástico Julio Plaza (2003), que inclusive escreveu uma tese com esse título e também traduziu 
para as artes plásticas, haicais e outras formas de arte. Desse modo, o caráter de tradução criativa que o figurino comporta é de um processo de "tradução intersemiótico" (PLAZA, 2003), transcriação em transmutação: transpõem-se os processos de escrita, presentes no texto e subtexto, para a composição de imagens materializadas em um personagem.

0 artista e teórico Plaza propôs a tradução intersemiótica como uma transcriação de formas, na qual é possivel a interpenetração de diferentes signos, recompondo suas relações estruturais e, sobretudo, estéticas. Plaza lida com as possibilidades de transposição de peças literárias e poéticas, traduzidas em outros códigos, em diferentes linguagens visuais ou sonoras, mas sempre preservando a ideia e a estrutura de funcionamento da peça original. A tese de Plaza (2003) é resultado de seu próprio trabalho como artista multimídia, e sua teoria é endereçada a questões que dão à tradução seu cunho intersemiótico.

A concepção das vestes e dos acessórios que compõem um personagem extrapolam as ações literalmente descritas em um texto, o figurinista deve ser capaz de continuar a desenvolver ações e escolhas de "moda" dos personagens, abrindo possibilidades de devir existencial e cênico. 0 subtexto, um dos elementos mais significativos e potencializadores da criação de figurino, foi definido por Jacob Guinsburg (2009) como constituidor dos elementos climáticos, conectados aos estados de alma, com ênfase na psicologia e na subjetividade. Ademais, o crítico e professor destaca, como sua função, o sentido de ir além do texto em desdobres inéditos, tanto nos movimentos de decodificações literárias e teatrais como cinematográficas.

[...] a tradução de um conjunto de palavras dispostas num espaço, que antes era o do papel, com vistas a uma concretização audiovisual, requer uma nova espécie de signo. Em muitos casos, o significado do texto escrito e do encenado podem até ser idênticos, mas o estabelecimento de uma constelação de signos concretamente materializados faz com que se tenha um outro tipo de linguagem que, embora pertença ao mesmo código, possui uma sintaxe específica por não estar colocado no mesmo meio que a outra. Daí a exigência de uma tradução, que é uma criação, na medida em que o texto sempre possui possibilidades interpretativas. (GUINSBURG, 2009 , p. 121)

0 figurino tem como função a constituição da identidade dos personagens, na maioria das vezes ficcional ou estilizada: "efeitos infinitos que dispõem na representação de si mesmo e na projeção de signos ou imagens que ele projeta na cena" (CORTINHAS, 2010, p. 7). Desse modo, é constituido o processo tradutório-operatório do personagem, por meio do figurino, no contexto de criação cênica.

0 figurino, da mesma maneira, é composto por todas as roupas e acessórios que os personagens usam, seja em filme, peça de teatro, novela ou manifestação artística. Sua função é caracterizá-los tanto física quanto psicologicamente. Mais do que apenas colocar uma roupa de lã quando a cena se passa no frio, o figurino é responsável pela materialização, através das roupas, dos sentimentos, ideias e valores do personagem em questão. (PUCCINI, 2009, p. 2)

A composição do figurino se alimenta, além do próprio texto, de territórios da arte, do pensamento de artistas, da moda, da história e do próprio espírito do tempo (PUCCINI, 2009). Ao pensar os conceitos trabalhados pelo traje em cena, 
o figurinista procura a melhor forma de criação tradutória de sentidos. 0 figurino torna-se a identidade visual do personagem,

e como instrumento à serviço da intenção estética da cena e do ator, deve ainda ser dotado de uma existência visual à maneira dos fantasmas. Um pouco invisivel para que o espectador tenha espaço para formular os seus próprios pensamentos. (CORTINHAS apud PUCCINI, 2009, p. 9)

Assim, o figurino, ao compor o personagem, também faz narrativa, "deveria contar uma história de transformação não como um signo verossímil, mas como um instrumento funcional, um argumento de significação" (CORTINHAS, 2010, p. 13). 0 trabalho do figurinista deve partir de uma exploração do texto na forma de roteiro, peça ou outro, e buscar um modo de expressão, na realidade da roupa, buscar um tipo de articulação imanente ao corpo, que traduza o personagem e sua constituição como sujeito cênico. Dessa forma, entendemos o figurino como roupa subjetiva: "o vestuário como uma das variáveis que se ligam à constituição do sujeito" (MESQUITA, 2007, p. 13).

Criar um figurino é atribuir uma tradução ao texto, dramatizá-lo em formas vestíveis, ecoando determinado significado, que já existia no original, como a sua possibilidade mesma de existir. Essas traduções em vestes mantêm encontros, mesmo que fugidios, com a linguagem verbal de partida: "uma espécie de língua estrangeira, que não é uma outra língua, nem um dialeto regional redescoberto, mas um devir-outro da língua, uma minoração" (DELEUZE, 2008, p. 15). Nesses procedimentos tradutórios, o figurinista atua de forma antropófaga, deglutindo os elementos textuais e recompondo existências em imagens. "Antropofagia, a resposta para a irônica equação do problema da origem é uma espécie de desconstrução" (CAMPOS, 2011, p. 126). Oswald de Andrade (1928), no Manifesto antropofágico (apud Campos, 2011, p. 126), proclama: "Só me interessa o que não é meu". Assim, essa deglutição antropofágica pode servir como metodologia poética na criação de indumentárias, por via de uma transculturação apropriação do que é estrangeiro para a construção de materialidades outras.

Corazza $(2013$, p. 210) lembra um poema de Augusto de Campos e nos diz que essa tradução transcultural "consiste numa questão de forma, mas também de alma".

recriar é a meta/ de um tipo especial/ de tradução: /a tradução-arte/ mas para chegar à/ re-criação/ é preciso identificar-se/ profundamente/ com o texto original/ e ao mesmo tempo/ não barateá-lo/ enfrentar todas as suas/ dificuldades/ tentar reconstituir/ a criação/ a partir de cada palavra/ som por som/ tom por tom/ é uma questão de forma/ mas também/ é uma questão de alma. (Augusto de Campos, 1986, 2ª orelha)

\section{Considerações finais}

Este estudo se constitui como pesquisa conceitual operatória ao trazer a noção de tradução para além da tradução entre línguas. Apresentando o conceito de tradução criativa e transcriação, este texto inicia expondo alguns questionamentos sobre a função criadora da moda, por sua excelência inovadora e signo tradutor da contemporaneidade. A pesquisa é levada a outro campo de estudo 
vinculado à disciplina moda, a saber, o figurino. 0 destaque tradutório é a função do figurino relacionada à transposição de um texto escrito, manifestado em linguagem verbal, para ser exposto em cena com função dramática e de construção de personagens, embora sua materialidade possa se dar de outras formas e nem sempre lidar com identidades e textos.

0 movimento de criação de um figurino descobre, escava a organicidade e os elementos materiais que outorgam poeticidade ao texto, cabe ao "figurinista-tradutor" liberar transitividade à língua de chegada, nesse caso, às vestes que materializam o personagem. Dessa forma, o figurinista busca despertar todas as estranhezas e caracteres que o original provoca no leitor-autor que lê e re-cria 0 texto em outros domínios. Essa operação de tradução em figurino é um processo de desvestimento de significados, desocultamento de signos para ir ao encontro do personagem em cena, da materialização de sua identidade. Com base em uma esfera textual, o figurinista age como Dr. Frankenstein e retoma vida a uma criatura que outrora só habitara o território das palavras. A essa tradução de palavras em imagens, chamamos de "tradução intersemiótica". Tradução que não se refere a um mero transportar ou transpor termos de uma língua para outra, mas sim verter e recriar palavras em indumentárias cênicas: transbordando a identidade do personagem para muito além do texto, fazendo-o ressoar em cena.

Com isso, transladamos por meio de um figurino, signos da linguagem verbal para signos não verbais. Como prática transcriadora, a construção das roupas dos personagens em uma produção audiovisual reconstitui informações estéticas presentes no texto e, sobretudo, em suas entrelinhas. A construção do figurino, portanto, não traduz um texto linha a linha, palavra por palavra, mas poetiza suas subjetividades em formas de vestir. 


\section{REFERÊNCIAS}

ARTAUD, Antonin. 0 teatro e seu duplo. São Paulo: Martins Fontes Editora, 2006.

ACOM, Ana Carolina Cruz. Didática cinemática: escrileituras em meio à filosofia-educação. Porto Alegre, 2015. Dissertação (Mestrado) - Programa de Pós-Graduação em Educação, Faculdade de Educação, Universidade Federal do Rio Grande do Sul.

CAMPOS, Augusto de. 0 anticrítico. São Paulo: Companhia das Letras, 1986.

CAMPOS, Haroldo de. Da transcriação: poética e semiótica da operação tradutora. Belo Horizonte: Fale/ UFMG, 2011.

Ensaio de meta-metalinguagem. In: Revista USP, São Paulo, pp. 55-70, jun./jul./ago. 1989.

Metalinguagem \&t outras metas. São Paulo: Perspectiva, 2006.

CARRIĖRE, Jean-Claude. A linguagem secreta do cinema. Rio de Janeiro: Nova Fronteira, 1995.

CASTILHO, Kathia. Moda e linguagem. São Paulo: Anhembi, 2004.

CORAZZA, Sandra Mara. Didática da tradução, transcriação do currículo: uma escrileitura da diferença. In: Pro-Posições. Campinas, v. 26, n. 1 jan./abr. 2015.

0 que se transcria em educação? Porto Alegre: Supernova Editora, 2013.

CORTINHAS, Rosângela. Figurino: um objeto sensivel na produção do personagem. Porto Alegre, 2010. Dissertação (Mestrado) - Programa de Pós-Graduação em Artes Cênicas, Instituto de Artes, Universidade Federal do Rio Grande do Sul.

CUNHA, Renato. Cinematizações: ideias sobre literatura e cinema. Brasília: Círculo de Brasília, 2007.

DELEUZE, Gilles. Crítica e clínica. São Paulo: Editora 34, 2008.

Deux régimes de fous. Paris: Les Éditions de Minuit, 2003.

GUATTARI, Félix. O que é a filosofia? São Paulo: Editora 34, 1997.

GUINSBURG, Jacó. A cena em aula: itinerários de um professor em devir. São Paulo: EDUSP, 2009.

JAKOBSON, Roman. Linguística e comunicação. São Paulo: Cultrix, 2007.

MESQUITA, Cristiane. Moda contemporânea: quatro ou cinco conexões possíveis. São Paulo: Editora Anhembi Morumbi, 2007.

Políticas do vestir: recortes em viés. São Paulo, 2008. Tese (Doutorado) - Programa de Estudos Pós-Graduados em Psicologia Clínica, Faculdade de Ciências Humanas e da Saúde, Pontifícia Universidade Católica de São Paulo.

PAVIS, Patrice. 0 teatro no cruzamento de culturas. São Paulo: Perspectiva, 2008.

PLAZA, Julio. Tradução intersemiótica. São Paulo: Perspectiva, 2003.

PRECIOSA, Rosane. 0 design de moda com potência de um experimento. In: Conexão - Comunicação e Cultura. Caxias do Sul, v. 5, n. 10, jul./dez. 2006.

PUCCINI, Carolina Citton. 0 figurino como ligação entre a atuação, o público e a realidade. Porto Alegre, 2009. Artigo final de conclusão de curso. Pós-Graduação, Especialização em Moda, Criatividade e Inovação, Faculdade de Tecnologia SENAC/RS.

RUFFINI, Franco. A cultura do texto e a cultura do palco. In: BARBA, Eugênio; SAVARESE, Nicola. A arte secreta do ator: um dicionário de antropologia teatral. São Paulo/Campinas: Hucitec/UNICAMP, 1995.

SANTAELLA, Lúcia. Transcriar, transluzir, transluciferar: a teoria da tradução de Haroldo de Campos. In: MOTTA, Leda Tenório da (Org.). Céu acima: para um "tombeau" de Haroldo de Campos. São Paulo: Perspectiva, 2005. 